NBER WORKING PAPER SERIES

THE THEOREMS OF INTERNATIONAL TRADE WITH FACTOR MOBILITY

\author{
Wilfred J. Ethier \\ Lars E.O. Svensson
}

Working Paper No. 1115

NATIONAL BUREAU OF ECONOMIC RESEARCH 1050 Massachusetts Avenue Cambridge MA 02138

May 1983

The research reported here is part of the NBER's research program in International Studies and project in Productivity in the World Economy. Any opinions expressed are those of the authors and not those of the National Bureau of Economic Research. 


\section{THE THEOREMS OF INTERNATIONAL TRADE WITH FACTOR MOBILITY}

\section{Abstract}

This paper addresses the relation between goods trade and international factor mobility in general terms. Conditions for factor price equalization are derived for situations with trade in both goods and factors, as well as Rybczynski and Stolper-Samuelson theorems. A weak price version of the Heckscher-Ohlin theorem is presented, as well as stronger quantity versions.

The basic theorems of international trade, suitably interpreted, are shown to hold in their strong versions if the number of international markets is at least as large as the number of factors. The crucial dimensionality issue is hence not the relative number of goods and factors per se, but the number of international markets relative to the number of factors. Only the price version of the Heckscher-ohlin theorem fails to be essentially preserved by this condition.

Wilfred J. Ethier Department of Economics University of Pennsylvania 3718 Locust Walk CR Philadelphia, PA 19104

(215) 898-5105
Lars E.O. Svensson Institute for International Economic Studies University of Stockholm S-106 91 Stockholm Sweden

08-16 3070 , or -163075 
THE THEOREMS OF INTERNATIONAL TRADE WITH FACTOR MOBILITY*

by

by Wilfred J. Ethier and Lars E.O. Svensson

University of Pennsylvania and Institute for International

Economic Studies, University of Stockholm

\section{Introduction}

This paper addresses the relation between commodity trade and international factor mobility in general terms. There are two motivations. The first is the intrinsic importance of the subject relative to the limited attention it has thus far received. Multi-commodity and multi-factor generalizations of the standard factor proportions theory of international trade deal mostly with goods trade only and ignore international mobility of factors of production (see Ethier $(1982 \mathrm{~b}$ ) for a recent survey). Although there exists an extensive literature on various aspects of international factor mobility (surveyed in Jones and Neary (1982)), there are few attempts systematically to discuss the trade pattern in both goods and factors when some factors are traded. Such a discussion is contained in Svensson (1982), who extends previous work by Dixit and Woodland (1982) to trade in factors as well as in goods. But Svensson's analysis deals only with marginal factor endowment differences in the neighborhood of an autarky equilibrium. Thus a more general treatment is needed.

Our second motivation is the dimensionality issue. As is well known, the standard theorems of factor-endowments trade theory are very sensitive to whether the number of goods equals the number of factors or not. ${ }^{1}$ This is widely regarded as very damaging to the theory, since the 
relative abundance of goods and factors is an arbitrary feature of nature and technology, and one about which most of us have limited intuition. Ethier (1982b) presents a countervailing argument assigning factor mobility a key role. There are two parts to the argument. (i) Those traditional results which are otherwise quite general, with equal numbers of goods and factors, are weakened only slightly when goods outnumber factors but substantially when factors outnumber goods. Thus the key requirement is that there be at least as many goods as factors, not that they be precisely equal in number. (ii) The main reason dimensionality matters is not the technological distinction between goods and factors, but the assumption that the former are internationally traded while the latter are not. Thus the standard results are preserved when factors outnumber goods if enough factors are traded. This interpretation leaves the basic propositions sensitive mainly not to an arbitrary feature of nature but to whether enough markets exist -- to which most substantive results in economics are sensitive. In any event, this discussion implies a central role for factor mobility in an understanding of the significance of the basic propositions of factor endowments trade theory. Our paper is organized as follows. Section 2 sets out the basic framework, and then Section 3 offers a full treatment of factor-price equalization, ${ }^{2}$ exposing the role of dimensionality. Section 4 derives some Rybczynski-type and Stolper-Samuelson type results. The relation of commodity trade and factor trade to each other and to factor endowments is the topic of the Heckscher-Ohlin type results of Section 5, which thereby also extend the previous analysis in Svensson (1982) of marginal factor endowment differences. Section 6 contains a summary and some conclusions. 


\section{International Equilibrium}

Consider a world of two countries, home and foreign. First we describe the home country. There are $M$ goods, indexed $i=1, \ldots, M$, all of which are traded. They are produced by $\mathrm{N}$ factors, $\mathrm{N}_{\mathrm{T}}$ of which are traded and $\mathrm{N}_{\mathrm{N}}$ of which are not. Factor endowments are fixed.

There are $J$ (production) sectors, indexed $j=1, \ldots, J$. Each production sector is characterized by a convex technology $\mathrm{T}^{j}$ of feasible combinations $\left(y^{j}, v^{j}\right)$ of net output M-vectors $y^{j}$ of goods and non-negative input $\mathrm{N}$-vectors $\mathrm{v}^{j}$ of factors. In particular, there are no externalities between sectors. (Indeed, sectors are defined as the finest partition of the overall production technology for which there are no intersectoral externalities.)

By using this concept of sectors, we can include joint production. 3 For the special case of no joint production, we can identify sectors with goods, and for sector $j$ all $\left(y^{j}, v^{j}\right)$ in $T^{j}$ will have $y_{j}^{j}>0$, and $y_{i}^{j}=0$ for all goods $i$ other than $j$.

For given goods prices $p$ and factor inputs $v^{j}$, the sector $j$ product function is defined as $G^{j}\left(p, v^{j}\right)=\max \left\{p^{-} y^{j}:\left(y^{j}, v^{j}\right) \varepsilon T^{j}\right\}$, the maximum value added obtainable, where $p^{-} y^{j}$ denotes the inner product $\Sigma_{i} p^{i} y_{i}^{j}$ (or, equivalently, the matrix product between the row vector $p^{-}$and the column vector $\mathrm{y}^{j}$; we let all vectors without a prime be column vectors, and let prime denote transpose). For a given domestic factor input $v$, the domestic product function is defined as $G(p, v)=\max \left\{\Sigma_{j} G^{j}\left(p, v^{j}\right): \Sigma_{j} v^{j}<v\right\}$, the maximum value of domestic output when factors are freely mobile between 
sectors. We let $v=\left(k^{-}, l^{-}\right)^{-}$denote home factor endowments, where the $\mathrm{N}_{\mathrm{T}}$-vector $\mathrm{k}$ denotes ownership of traded factors and the $\mathrm{N}_{\mathrm{N}}$-vector $\ell$ denotes endowments of nontraded factors. For simplicity we shall call these "capital" and "labor", respectively. Let the $\mathrm{N}_{\mathrm{T}}$-vector $\tilde{\mathrm{k}}$ denote capital input in production (as distinct from capital endowments) in the home country, and let the $\mathrm{N}_{\mathrm{T}}$-vector $r$ denote rentals, the price of capital. Then, for given goods prices and rentals, and given factor endowments, we define the national product function $\tilde{G}(p, r, v)$ as

$$
\tilde{G}(p, r, k, l)=G(p, \tilde{k}(p, r, l), \ell)+r^{\prime}(k-\tilde{k}(p, r, l)) .
$$

Here the capital input function $\tilde{k}(p, r, l)$ is the solution to $\max \{G(p, \tilde{k}, l)+$ $r^{\prime}(k-\tilde{k}): \tilde{k}>$ 아, which then fulfills 4

$$
G_{k}(p, \tilde{k}(p, r, \ell), \ell)=r
$$

Hence we assume each sector behaves competitively, and takes goods prices and rentals as given. The first term on the right hand side of (1) is domestic product from the use of factors $(\tilde{k}, l)$ at home, and the second term is factor income from abroad, due to the net export of capital (k - $\tilde{k})$, the difference between endowments and domestic input of capital.

$$
\text { Assume that the demand side of the home country can be represented }
$$
by a standard M-vector demand function $D(p, Y)$, where $Y$ is national income. We define net export of goods, $x$, and of capital, $z$, as

$$
x=y-c \text { and } z=k-\tilde{k} \text {, }
$$

the difference between output $y$ and consumption (M-vector) $c$, and between capital 
endowments and capital input. By standard properties of the national product function, net export of goods and capital will be given by the functions 5

$$
\begin{aligned}
& x(p, r, v)=\tilde{G}_{p}(p, r, v)-D(p, \tilde{G}(p, r, v)), \text { and } \\
& z(p, r, v)=\tilde{G}_{r}(p, r, v)=k-\tilde{k}(p, r, l) .
\end{aligned}
$$

Furthermore, the prices of nontraded factors, wages $w$, will be given by

$$
w=\tilde{G}_{\ell}(p, r, v)
$$

The foreign country has factor endowments $\mathrm{v}^{*}=\left(\mathrm{k}^{*}, l^{*}\right)$ and analogous national product and demand functions, which give rise to net export functions for goods and capital, denoted by $x^{*}\left(p, r, v^{*}\right)$ and $z^{*}\left(p, r, v^{*}\right)$. A world equilibrium will satisfy

$$
\begin{aligned}
& x(p, r, v)+x^{*}\left(p, r, v^{*}\right)=0, \text { and } \\
& z(p, r, v)+z^{*}\left(p, r, v^{*}\right)=0
\end{aligned}
$$

that is, both goods and traded-factor markets are in equilibrium.

\section{Factor Price Equalization}

We first determine when free trade in goods and capital will internationally equalize the rewards of nontraded factors. To this end we now assume that the two countries have identical technology with constant returns to scale. Then $\tilde{G}(p, r, v)$ is linearly homogeneous in $v, \tilde{k}(p, r, l)$ is linearly homogeneous in $\ell$, and the functions apply to both countries. 
To establish a point of reference, suppose initially that the world's stock of factors is distributed between the two countries so as to render the foreign endowment proportional to the home: $v^{*}=\lambda v$. Thus the two countries are initially identical in all respects save possibly tastes and scale.

Under these circumstances, a possible free-trade equilibrium, (7) and (8), is obtained if each country produces a scaled-down version of the world output vector, if no capital is actually traded, and if goods are traded to accommodate taste differences. (Depending upon dimensionality, there may be other equilibria as well, with the same prices, but this possibility will not disturb our subsequent argument. We assume that the equilibrium price vector is unique, up to a multiplicative factor.) That is, we have

$$
x+x^{*}=0 \text { and } z=z^{*}=0
$$

Also, $w=\tilde{G}_{\ell}(p, r, v)=\tilde{G}_{\ell}(p, r, \lambda v)=w^{*}$, so that the prices of nontraded factors are equalized. We wish to know the circumstances under which this equalization is preserved when we abandon the assumption that endowments in the two countries are strictly proportional to each other.

As a first step, let the relative endowments depart marginally from proportionality by perturbing the above equilibrium by redistributing endowments: 6

$$
d v+d v^{*}=0, \text { with } w^{-} d v=w^{-} d v^{*}=0
$$


where $w^{-}=\left(r^{-}, w^{\prime}\right)$. Then, from $(7)$ and $(8)$

$$
\begin{aligned}
& \left(x_{p}+x_{p}^{*}\right) d p+\left(x_{r}+x_{r}^{*}\right) d r=-\left(x_{v}-x_{v}^{*}\right) d v=0 \text { and } \\
& \left(z_{p}+z_{p}^{*}\right) d p+\left(z_{r}+z_{r}^{*}\right) d r=-\left(z_{v}-z_{v}^{*}\right) d v=0
\end{aligned}
$$

as consequences of homogeneity. Here $x_{p}$ is the $M x M \operatorname{matrix}\left[\partial x_{i} / \partial p_{j}\right]$, etc. Then $d p=0$ and $d r=0$ is consistent with maintaining free trade equilibrium. In this case, wages in the two countries change according to

$$
\begin{aligned}
& d w=\tilde{G}_{\ell v} d v=\tilde{G}_{\ell \ell} d \ell, \text { and } \\
& d w^{*}=G_{\ell v^{*}} d v^{*}=-G_{\ell \ell}^{*} d \ell,
\end{aligned}
$$

where we have used $G_{\ell k}=0$; that is, wages do not directly depend on capital endowments. ${ }^{7}$ Now, since the national product function is linearly homogeneous in factor endowments, its first derivatives are of zero homogeneity, and its second derivatives are homogeneous of degree minus one. Hence,

$$
\tilde{G}_{\ell \ell}^{*}(, \lambda v)=\tilde{G}_{\ell \ell}(, \lambda v)=\tilde{G}_{\ell \ell}(, v) / \lambda \text {. }
$$

It follows that

$$
d w-d w^{*}=\left(\tilde{G}_{\ell \ell}+\tilde{G}_{\ell \ell}^{*}\right) d \ell=(\lambda+1) \tilde{G}_{\ell \ell} d \ell / \lambda,
$$

and we see that wages remain equalized if $\tilde{G}_{\ell \ell}$ is equal to zero; that is, if changes in labor endowments have no (local) effect, at constant goods prices and rentals, on wages. 
To show that $\tilde{G}_{\ell \ell}$ indeed equals zero, under the assumptions of identical technologies, constant returns to scale, and initially proportional endowments, we employ the unit value added cost function, as follows.

For each sector $j$, the unit value added cost function $c^{j}(p, W)$ is defined as 8

$$
C^{j}(p, w)=\min \left\{w^{-} v^{j}: p^{-} y^{j}=1,\left(y^{j}, v^{j}\right)_{\varepsilon} T^{j}\right\}
$$

This cost function gives, for given goods prices (the M-vector $p$ ) and factor prices (the $N$-vector $W$ ), the minimum value of inputs for which value added, the value of the net output vector, is equal to unity. Let $\mathrm{Y}^{j}$ denote value added in sector $j$; let $Y=\left(Y^{j}\right)$ be the corresponding $J$-vector; and let $C(p, W)$, the national cost function, be the vector whose components are the cost functions for the sectors with positive value added. That is, ${ }^{9}$ let $J(Y)=\left\{j: j \varepsilon J, Y^{j}>\right.$ of (the set of sectors with positive value added) and $C(p, W)=\left(C^{j}(p, W)\right)_{j \in J(Y)^{*}}$ (We suppress the argument $Y$, or $J(Y)$, of the national cost function.) The national cost function is homogeneous of degree zero in goods prices and factor prices. Then, by Euler's theorem

$$
\mathrm{p}^{\prime} \mathrm{C}_{\mathrm{p}}+\mathrm{W}^{-} \mathrm{C}_{\mathrm{W}}=0
$$

where $\mathrm{p}^{-} \mathrm{C}_{\mathrm{p}}$ denotes pre-multiplication of the (row) M-vector $\mathrm{p}^{-}$by the $(M \times J(Y))$-matrix $C_{p}=\left[a C^{J} / \partial p^{i}\right]$, etc. Since $W^{-}=\left(r^{\prime}, W^{\prime}\right)$ and in equilibrium $\tilde{G}_{\ell}=w$, we can write

$$
\tilde{G}_{\ell}-C_{w}=-p^{\prime} C_{p}-r C_{r}
$$

We note that the matrix $C_{w}=\left[\partial C^{j} / \partial w^{i}\right]$ is $N_{N} \times J(Y)$. If $J(Y)>N_{N}$, 
$\mathrm{C}_{\mathrm{w}}$ is square or can be made so by arbitrary deletion of enough equations (that is, sectors) from (18). If so, and if $\mathrm{C}_{\mathrm{W}}$ thus modified is of rank $\mathrm{N}_{\mathrm{N}}$, it is invertible, and we can write

$$
\tilde{G}_{\ell}^{-}=-\left(p^{-} C_{p}+r C_{r}\right) C_{w}^{-1}
$$

Here the right hand side does not depend on labor input $\ell .{ }^{10}$ We hence conclude that $\tilde{G}_{\ell \ell}$ equals zero, and from (15) we have factor price equalization, and

$$
d w=d w^{*}=0 .
$$

The sufficient condition for this is

$$
J(Y)>N_{N}=\operatorname{rank} C_{W} \text {, }
$$

that is, there must be as many linearly independent (that is, distinct) sectors with positive value added as there are non-traded factors. If the equilibrium vector $Y$ of value added is unique, (2l) holds with equality and the number of sectors is exactly equal to the number of non-traded factors.

The next step is to consider large international differences in relative endowments. The above argument applies to all finite changes $\Delta v$ and $\Delta v^{*}$ consistent with (10), for which neither country is forced to shut down any sector. ${ }^{11}$ When will this be so?

To see this, first recall that the price derivatives of the cost function, in equilibrium, are conditional unit value added input functions. 12 Then we can write the home country's output, capital input and labor input as 
(22)

$$
y=-C_{p} Y, \tilde{k}=C_{r} Y \text { and } \ell=C_{w} Y \text {, }
$$

where $C_{p} Y$ denotes post-multiplication of the matrix $C_{p}=\left(\partial C^{j} / \partial p^{i}\right)$ by the (column) vector $Y$, etc. Let us now define the generalized diversification cone $K(p, r, w)$ as

$$
K(p, r, w)=\left\{\ell>0: \ell=C_{W} Y, Y>0\right\}
$$

It is, for given goods and factor prices, the set of labor inputs consistent with non-negative value added in all sectors. The diversification cone is of dimension $N_{N}$ if (21) holds. To assure that the output vector is unique, we assume that (2l) holds with equality. Then $\mathrm{C}_{\mathrm{w}}$ is square and can be inverted, and we can use (22) to get

$$
\mathrm{y}=-\mathrm{C}_{\mathrm{P}} \mathrm{C}_{\mathrm{w}}^{-1} \ell \text {, and } \tilde{\mathrm{k}}=\mathrm{C}_{\mathrm{r}} \mathrm{C}_{\mathrm{W}}^{-1} \ell \text {. }
$$

Now, suppose the world is in the initial equilibrium, and consider changes $\Delta \mathrm{v}$ and $\Delta \mathrm{v}^{*}$ consistent with $(10)$, and leaving $\ell$ and $\ell^{*}$ in the diversification cone. Is this consistent with a new equilibrium with unchanged goods and factor prices? If, in fact, these do not change, we have by (24)

$$
\begin{aligned}
& \Delta\left(\mathrm{y}+\mathrm{y}^{*}\right)=\Delta\left[-\mathrm{C}_{\mathrm{p}} \mathrm{C}_{\mathrm{w}}^{-1}\left(\ell+\ell^{*}\right)\right]={ }_{-} \mathrm{C}_{\mathrm{p}} \mathrm{C}_{\mathrm{w}}^{-1}\left(\Delta \ell+\Delta \ell^{*}\right)=0 \text { and } \\
& \Delta\left(\tilde{\mathrm{k}}+\tilde{\mathrm{k}}^{*}\right)=\Delta\left[\mathrm{C}_{\mathrm{r}} \mathrm{C}_{\mathrm{w}}^{-1}\left(\ell+\ell^{*}\right)\right]=\mathrm{C}_{\mathrm{r}} \mathrm{C}_{\mathrm{w}}^{-1}\left(\Delta \ell+\Delta \ell^{*}\right)=0 .
\end{aligned}
$$

Thus world output of goods and world input of capital remin unchanged. Since world demand for goods and world endowments of capital are unchanged, 
world markets for goods and capital remain in equilibrium.

It follows that for changes $\Delta v$ and $\Delta v^{*}$ that fulfill (10) and leave $\ell$ and $\ell^{*}$ in the diversification cone, there exists a new equilibrium with unchanged goods and factor prices and hence factor price equalization. But are we sure that there do not still exist other equilibria, where factor price equalization does not obtain? To dispose of this possibility, assume there exist wage vectors $w^{0}$ and $w^{1}$, with $w^{1} \neq w^{0}$, and let $\ell$ be in both $K\left(p, r, w^{0}\right)$ and $K\left(p, r, w^{1}\right)$. Then there exist $Y^{0}$ and $Y^{1}$ such that

$$
\ell=C_{W}^{0} Y^{0} \text { and } \ell=C_{W}^{1} Y^{1}
$$

where $C_{W}^{0}$ and $C_{W}^{1}$ denote $C_{W}\left(p, r, w^{0}\right)$ and $C_{W}\left(p, r, w^{l}\right)$. Furthermore, by zero homogeneity of the national cost function, we have

$$
-p^{-} c_{p}^{0}=r^{-} C_{r}^{0}+w^{0}-c_{w}^{1} \text { and }-p^{-} C_{p}^{1}=r^{-} C_{r}^{1}+w^{1}-C_{w}^{1} \text {, }
$$

with obvious notation.

Recalling that the derivatives are conditional input demands, since the input demands minimize cost, we also have

$$
r-c_{r}^{0}+w^{1}-c_{w}^{0}>-p^{-} c_{p}^{0}=r-C_{r}^{0}+w^{0}-c_{w}^{0}
$$

with at least one inequality strict if $\mathrm{w}^{1} \neq \mathrm{w}^{0}$. Thus $\mathrm{w}^{1}-\mathrm{C}_{\mathrm{w}}^{0}>\mathrm{w}^{0}-\mathrm{C}_{\mathrm{w}}^{0}$, so

$$
\left(w^{1}-w^{0}\right)-C_{W}^{0} Y^{0}=\left(w^{1}-w^{0}\right)-l>0,
$$

with strict inequality if $w^{1} \neq w^{0}$. By a symmetric argument, we can show

$$
\left(w^{0}-w^{1}\right)-\ell>0 \text {, }
$$

with strict inequality if $w^{0} \neq w^{1}$. It follows that $w^{1}=w^{0}$, contrary to what 
was assumed at first.

Hence, factor price equalization must obtain, if the endowment changes fulfill (10) and leave both countries' labor endowments in the diversification cone. The crucial condition is (21). If there is no joint production, this reduces to

$$
\mathrm{M}+\mathrm{N}_{\mathrm{T}}>\mathrm{N}
$$

That is, the total number of international markets (goods and traded factors) must be at least as great as the number of factors. This indicates that at bottom factor price equalization depends not on an arbitrary aspect of nature (the relative numbers of goods and factors) but rather, just like most interesting propositions in economics, on the existence of enough markets. Note, however, that the number of markets which is sufficient depends upon the number of factors (so that reducing the number of goods and increasing the number of traded factors a like amount is not neutral: the required number of international markets rises).

$$
\text { At this point we must say a word about nontraded goods. They }
$$

should of course be allowed if commodities are to be treated analogously to factors. We exclude them for expositional reasons, since they do not affect our basic argument. If included, conditions for equilibrium in nontraded goods markets would be solved for nontraded goods prices as functions of the present state variables, and these functions would simply be embodied in the form of the national product functions, and so forth. Then, provided proper care were taken in the use of the diversification-cone concept, the argument 
of this section would proceed essentially unchanged. 13 In particular, (21) would remain the key dimensionality condition. Note that this indicates a way in which factors and goods differ: an additional nontraded factor makes (21) more stringent, but an additional nontraded good does not.

\section{Comparative Statics}

In factor-endowments models of commodity trade, the Rybczynski theorem describes the effects of endowment changes on outputs, and the Stolper-Samuelson theorem addresses the implications of commodity-price changes for factor rewards. ${ }^{14}$ Both propositions exploit the technological relation between goods and factors and do not depend upon whether factors are internationally traded or not (although the latter might help determine the circumstances under which the theorems can in fact be applied). For example, the Rybczynski theorem's description of how commodity outputs respond to changes in a nation's employment of factors is not sensitive to whether the latter changes are due to domestic factor accumilation or to the import of traded factors. Thus we need say little about the influence of factor trade on the standard propositions. Instead we focus on the new questions that arise.

There are three relevant aspects to the two theorems. First, they are linked together by the "reciprocity relations." Next, each of the theorems contains two assertions, one relating to magnitudes and one relating to directions. For example, the Stolper-Samuelson theorem asserts that commodity price changes produce unambiguous changes in real factor rewards, 
and also that relative factor intensities help to predict the direction of the latter. We examine in turn each of the three aspects.

\section{(i) The reciprocity relations}

The standard reciprocity relations follow from differentiation of the domestic product function. We have $G_{v p}=G_{v p}^{\prime}$, where again a prime denotes transpose. Hence, for good $i$ and factor $j$,

$$
\partial y^{i} / \partial v^{j}=\left(\partial / \partial v^{j}\right)\left(\partial G / \partial p^{i}\right)=\left(\partial / \partial p^{i}\right)\left(\partial G / \partial v^{j}\right)=\partial w^{j} / \partial p^{i} \text {. }
$$

These relations hold whenever the respective terms are well defined. They reflect only the technology (and the optimization implicit in the domestic product function) and these hold regardless of whether factor $j$ is traded or nontraded. But the presence of traded factors introduces the questions of how changes in the endowments of nontraded factors influence a country's use of traded factors, and of how changes in the (international) price of traded factors affect the rewards of nontraded factors. We therefore derive an appropriate set of reciprocity relations. This is not difficult. For we have, using twice-differentiability of the national product function,

$$
\tilde{G}_{r \ell}=\tilde{G}_{\ell} \tilde{r}^{\prime}
$$

and since, by (5) and (6),

$$
\tilde{\mathrm{w}}_{r}=\tilde{\mathrm{G}}_{\ell r} \text { and }-\tilde{\mathrm{k}}_{\ell}=\tilde{\mathrm{G}}_{\mathrm{r} \ell} \text {, }
$$

we get the desired reciprocity relation

$$
-\partial \tilde{k}^{i} / \partial \ell^{j}=\partial \tilde{w}^{j} / \partial r^{i} \text {, }
$$

for traded factor $i$ and nontraded factor $j$. 


\section{(ii) Magnitudes}

It is well known that the following results hold under very general circumstances when $M=N$ and there is no joint production: (a) an increase in the price of any good causes a more-than-proportional rise in some factor reward and a decline in some other factor reward; (b) at given commodity prices, an increase in the economy-wide use of any factor requires a more-than-proportional rise in the output of some good and an absolute fall in the output of some other good; (c) application of the reciprocity relations (32) to the "Stolper-Samuelson" result (a) yields further "Rybczynski" results and application to the "Rybczynski" result (b) yields further "Stolper-Samuelson" results. If there are more goods than factors these results are almost completely preserved, but they are weakened substantially when the number of factors exceeds the number of goods. 15

The presence of traded factors has little effect on these propositions: the results follow whenever the conditions are met. But two points should be made. First, the above results are weakened when there are more factors than goods because endowment changes at constant prices then require changes in factor rewards for factor markets to clear. Thus the analysis of the previous section implies that, with traded factors, condition (31) replaces $M>N$ as the dimensionality requirement for the results to hold in full strength: there must be at least as many international markets as factors.

The second point concerns the relation between traded and nontraded factors. Suppose an exogenous rise in the reward of some traded factor, all 
other international prices remaining fixed. Then some factor reward mast fall, else no sector would be able to earn non-negative profits at unchanged commodity prices. With the rewards of traded factors fixed, it must be a nontraded factor that becomes cheaper. Furthermore, this is a real decline since commodity prices have not changed. Thus each traded factor is an "enemy" to some nontraded factor. The reciprocity relations (35) then imply that the demand for any traded factor is reduced by a rise in the endowment of some single nontraded factor. Note that these results do not require condition (31) and that they are fully compatible with joint production.

\section{(iii) Directions}

In factor-endowments trade models, factor intensities predict, in an average sense, the response of factor rewards to commodity-price changes and the response of outputs to factor-endowment changes. For example, commodity-price changes are positively correlated with changes in the rewards of those factors used relatively most intensively (see Ethier (1982a,b)). Such predictions are not sensitive to whether some factors are traded or not. 16 But now we are interested instead in predicting the direction of change of commodity outputs and traded-factor usage jointly in response to changes in the endowments of nontraded factors, and also in predicting changes in nontraded factor rewards in response to changes in the vector of commodity prices and traded-factor rewards. We have

$$
y=\tilde{G}_{p}(p, r, v) \text { and }-\tilde{k}=\tilde{G}_{r}(p, r, v)=-\tilde{k}(p, r, l) \text {. }
$$

Define $q=\left(y^{-},-\tilde{k}^{-}\right)^{-}$and $\pi=\left(p^{-}, r^{-}\right)^{-}$, where all vectors without primes are 
column vectors. Then we have

$$
q=\tilde{G}_{\pi}(\pi, k, l) \text {. }
$$

Consider the effects of an endowment change from $\ell^{0}$ to $\ell^{l}$, at given

international prices $\pi$. Let $\mathrm{q}^{1}=\tilde{G}_{\pi}\left(\pi, \mathrm{k}, \ell^{1}\right), \mathrm{q}^{0}=\tilde{G}_{\pi}\left(\pi, \mathrm{k}, \ell^{0}\right)$ and define the real-valued function

$$
a(\ell) \equiv\left(q^{1}-q^{0}\right)-\tilde{G}_{\pi}(\pi, k, l)
$$

By the mean-value theorem there exists an $\bar{\ell}$ on the line segment connecting $\ell^{0}$ and $\ell^{l}$ such that

$$
a\left(\ell^{1}\right)-a\left(\ell^{0}\right)=a_{\ell}(\bar{l})\left(\ell^{1}-\ell^{0}\right) .
$$

Substituting the definitions of these terms yields

$$
\begin{aligned}
& \left(q^{1}-q^{0}\right)-\left(q^{1}-q^{0}\right)=\left(q^{1}-q^{0}\right)-R\left(\ell^{l}-\ell^{0}\right) \text {, where } \\
& R=\tilde{G}_{\pi \ell}(\pi, k, \bar{l})=\left[\begin{array}{c}
\tilde{G}_{p \ell}(p, r, k, \bar{l}) \\
-\tilde{k}_{\ell}(p, r, \bar{l})
\end{array}\right] .
\end{aligned}
$$

Thus

$$
\left[\left(\mathrm{y}^{1}-\mathrm{y}^{0}\right)-\left(-\tilde{\mathrm{k}}^{1}+\tilde{\mathrm{k}}^{0}\right)-\operatorname{R}\left(\ell^{1}-\ell^{0}\right)>0 .\right.
$$

This is the general (directional) Rybczynski theorem for an economy with traded factors. Note that $R$ depends only upon technology. Using the term "relative factor intensities" to refer to the relative magnitudes of the elements of $R$, correlation (36) says that any change in the endowment of nontraded factors will, at constant prices of goods and traded factors, tend on average to raise the most the outputs of goods, and to reduce the most the 
usage of traded factors, that are relatively most intensive in the use of those nontraded factors that have increased the most, etc. Note that we look at the various commodities' intensity of use of nontraded factors only, but that these are compared not only with each other but also with the relative intensities of nontraded factors in the economy's usage of traded factors. (Nontraded factors can be thought of as "employed" in the national usage of traded factors in the sense that, given commodity outputs, an increased endowment of nontraded factors allows the economy to reduce its usage of traded factors). 17

This result is extremely general in that it allows joint production, applies to arbitrary endowment changes, and is independent of the relative numbers of goods, traded factors, and nontraded factors. Thus the movement from $\ell^{0}$ to $\ell^{1}$ may or may not change $w$. But for (36) to be useful we need to explore the nature of the key matrix $R$. To this end assume that there are the same number of goods as sectors. Then, if the matrix $-C_{p}$ in (22) is of full rank, it can be inverted. Doing so, (22) becomes

$$
\tilde{k}=-C_{r} C_{p}^{-1} y=-C_{r} C_{p}^{-1} \tilde{G}_{p} \text { and } \ell=-C_{w} C_{p}^{-1} y=-C_{w} C_{p}^{-1} \tilde{G}_{p}
$$

To proceed further we need further restrictions. Assume that condition (31) holds, so that our results from the previous section imply that a small deviation of $\ell$ about $\bar{l}$ produces no change in w. Then from (37)

$$
-\tilde{\mathrm{k}}_{\ell}=-\mathrm{C}_{\mathrm{r}} \mathrm{C}_{\mathrm{p}}^{-1} \tilde{\mathrm{G}}_{\mathrm{p} \ell} \text { and } \mathrm{I}=-\mathrm{C}_{\mathrm{w}} \mathrm{C}_{\mathrm{p}}^{-1} \tilde{G}_{\mathrm{p} \ell} \text {, }
$$

where I is the identity matrix. If, furthermore, (31) holds with equality, 
$\mathrm{C}_{\mathrm{w}} \mathrm{C}_{\mathrm{p}}^{-1}$ is square so that (assuming full rank) it can be inverted to yield $\tilde{G}_{\mathrm{pl}}=-\mathrm{C}_{\mathrm{p}} \mathrm{C}_{\mathrm{w}}^{-1}$ and hence

$$
R=\left[\begin{array}{c}
-{ }_{p} c_{w}^{-1} \\
C_{r} c_{w}^{-1}
\end{array}\right] .
$$

Here $-C_{p}^{-1} C_{w}$ is simply the matrix of nontraded factor requirements (at the intermediate point) in the respective sectors and $-C_{p}^{-1} C_{r}$ the matrix of traded factor requirements. If joint production is excluded, $\mathrm{C}_{\mathrm{p}}$ is the diagonal matrix whose diagonals are the inverse of the goods prices and can hence be made equal to the identity matrix by the proper choice of units of measurement of goods.

Continuing to suppose that (31) holds - but not necessarily with equality -- suppose that the hypothetical endowment change leaves the economy within the original generalized diversification cone. Thus no change in w will take place and the production techniques will likewise be unaltered. In this case $R$ can simply be calculated from the observed techniques. Note also that (37) now, under the assumption of no change in w, gives

(38a) $\quad\left(e^{1}-\ell^{0}\right)-\left(-C_{w} c_{p}^{-1}\right)\left(y^{1}-y^{0}\right)=\left(e^{1}-e^{0}\right)-\left(l^{1}-l^{0}\right)>0$ and (38b) $\quad\left(\tilde{k}^{1}-\tilde{k}^{0}\right)-\left[-c_{r} c_{p}^{-1}\right]\left(y^{1}-y^{0}\right)=\left(\tilde{k}^{1}-\tilde{k}^{0}\right) \cdot\left(\tilde{k}^{1}-\tilde{k}^{0}\right)>0$.

That is, the direct input requirements are in this case used to determine relative factor intensities.

We also show a Stolper-Samuelson analogue to (36). Consider the 
effect on nontraded factor prices $w$ of a change from goods and traded factor prices $\pi^{0}=\left(p^{0},, r^{0}-\right)$ to $\pi^{1}=\left(p^{l},, r^{l}-\right)$ - Starting from $w(\pi, v)=\tilde{G}_{\ell}(p, r, v)$, let $w^{l}=\tilde{w}\left(\pi^{l}, v\right)$ and $w^{0}=\tilde{w}\left(\pi^{0}, v\right)$, and define $b(\pi)=\left(w^{1}-w^{0}\right)-\tilde{G}_{\ell}(\pi, v)$. By the mean-value theorem, there exist $a \bar{\pi}$ on the line segment between $\pi^{0}$ and $\pi^{1}$ such that

$$
b\left(\pi^{1}\right)-b\left(\pi^{0}\right)=b_{\pi}(\pi)\left(\pi^{1}-\pi^{0}\right) .
$$

Substituting the definitions of these terms, we have the desired analogue to (36),

$$
\left(w^{1}-w^{0}\right)-\left(w^{1}-w^{0}\right)=\left(w^{1}-w^{0}\right)-S\left(\pi^{1}-\pi^{0}\right)>0 \text {, }
$$

where

$$
S=\tilde{G}_{\ell \pi}(\bar{\pi}, v)
$$

\section{Patterns of Trade in Goods and Factors}

In this section we develop versions, appropriate in the presence of factor trade, of the principle of comparative advantage and of the price and quantity versions of the Heckscher-Ohlin theorem.

\section{(i) The principle of comparative advantage}

General results relating the pattern of trade in goods only to differences in autarky goods prices have been obtained by Deardorff (1980) and Dixit and Norman (1980), and surveyed in Ethier (1982b). Factor trade can be straightforwardly incorporated. Letting $p^{A}$ and $r^{A}$ denote autarky prices and $c$, $y$ and $z$ denote free-trade consumption, output and factor exports, we have

$$
p^{A}, c>\bar{G}\left(p^{A}, r^{A}, v\right)>p^{A}-y+r^{A}, z
$$


The first inequality follows from standard gains-from-trade arguments, which easily encompass factor trade, 18 and the second inequality follows from the definition of $\tilde{G}$. Thus

$$
\pi^{A}-\left(x^{-}, z^{-}\right)<0
$$

where $\pi^{A}=\left(p^{A}, r^{A},\right)^{-}$and $x=y-c$. Now $\pi^{-}\left(x^{\prime}, z^{-}\right)^{-}=0$ if $\pi$ denotes free trade prices. Thus

$$
\left(\pi-\pi^{A}\right)-\left(x^{-}, z^{-}\right)^{-}>0
$$

Similar arguments applied to the foreign country yield

$$
\begin{aligned}
& \left(\pi-\pi^{A^{*}}\right)-\left(x^{*-}, z^{*-}\right)->0 . \\
& \text { Since }(x, z)+\left(x^{*}, z^{*}\right)=0 \text {, we have }
\end{aligned}
$$

$$
\left(\pi^{A^{*}}-\pi^{A}\right) \cdot\left(x^{-}, z^{-}\right) \cdot>0 \text {. }
$$

The great generality of our results (40) and (41) should be apparent.

(ii) The price version of the Heckscher-Ohlin theorem

Assume that the number of goods equals the number of sectors and that

$C_{p}$ is of full rank so that (17) implies

$$
p^{\prime}=r^{-}\left[-C_{r}^{-} C_{p}^{1}\right]+w^{-}\left[-\bar{C}_{w} C_{p}^{1}\right]
$$

Furthermore, assume no joint production. Then the right-hand side above depends on factor prices only and indeed the right-hand side is identical to the (row) vector of the standard unit-cost functions. Then we can write

$$
\pi^{-}=W^{\circ} D(W)
$$


where

$$
D(W)=\left[\begin{array}{cc}
-C_{r} C_{p}^{-1} & I \\
-C_{W} C_{p}^{-1} & 0
\end{array}\right] \text {. }
$$

Now define the real-valued function $d(W)$ by

$$
d(W)=W^{-} D(W)\left(x^{-}, z^{-}\right)^{-}
$$

where $\left(x^{-}, z^{-}\right)$denotes the actual free-trade vector of net exports of goods and factors. Let $W^{A}$ and $W^{A^{*}}$ denote autarky factor prices at home and abroad. Then, for some $\bar{W}$ between $W^{A}$ and $W^{A^{*}}$,

$$
d\left(w^{A}\right)-d\left(w^{A^{*}}\right)=\left(w^{A}-W^{A^{*}}\right)-d W(\bar{W}),
$$

or

$$
\left(\pi^{A}-\pi^{A^{*}}\right)-\left(x^{-}, z^{-}\right)=\left(W^{A}-W^{A^{*}}\right)-D(\bar{W})\left(x^{-}, z^{-}\right) .
$$

Here we have used $a_{W}(W)=D(W)\left(x^{-}, z^{-}\right)^{-}$, since by cost minimizing all terms $\Sigma_{j} W^{j} \partial D_{j i}(W) / \partial W^{i}$ are zero. The left-hand side of (42) is nonpositive by (41), so substituting for the right-hand side gives

$$
\left(r^{A}-r^{A^{*}}\right)-\left[-C_{r} C_{p}^{-1}\right] x+\left(w^{A}-w^{A^{*}}\right)-\left[-C_{w} C_{p}^{-1}\right] x+\left(r^{A}-r^{A^{*}}\right)-z<0
$$

where we recall that the direct capital input and labor input matrices $-C_{r} C_{p}^{-1}$ and $-C_{w} C_{p}^{-1}$ are evaluated at $\bar{W}$. The inequality (43) is a weak result, relative to the goal of predicting something about $(x, z)$ solely from $\left(w^{A}-w^{A^{*}}\right)$. Now we need to know $\left(r^{A}-r^{A^{*}}\right)$ as well, that is, we do not use a concept of relative factor abundance limited to nontraded factors only. The problem is that the latter do not in general give enough information if there are also traded factors. 
(iii) The quantity version of the Heckscher-Ohlin theorem

In factor-endowments trade theory, the quantity version of the Heckscher-Ohlin theorem is related to the Rybczynski theorem. We now wish to use our versions of the latter to develop explanations of the pattern of joint trade in goods and factors. To that end, we now define the vector $x^{P}$ and $x^{I}$ of home country "preference trade" and "induced trade", respectively, as follows

$$
x^{P}=g\left(y^{1}+y^{*}\right)-c \text { and } x^{I}=x-x^{P},
$$

where $c$ denotes the home consumption vector, $g$ the home-country share of the value of world output, and $y^{1}$ and $y^{*}$ denote home and foreign outputs respectively. Note that if the home and foreign countries share identical homothetic tastes, $x^{P}=0$ and $x=x^{I}$. Define $\ell^{0}=g\left(\ell^{1}+\ell^{*}\right)$, where $\ell^{1}$ and $\ell^{*}$ denote endowments of nontraded factors at home and abroad. Then, if $p$ and $r$ equal free trade equilibrium prices, we have from (36)

$$
\left[\left(\mathrm{y}^{1}-\mathrm{y}^{0}\right)-\left(-\tilde{\mathrm{k}}^{1}+\tilde{\mathrm{k}}^{0}\right)-\right] \mathrm{R}\left(e^{1}-e^{0}\right)>0
$$

where $y^{i}=\tilde{G}_{p}\left(p, r, k, l^{i}\right)=G_{p}\left(p, \tilde{k}^{i}, l^{l}\right)$ and $k^{i}=\tilde{k}\left(p, r, l^{i}\right)$ for $i=0,1$. Now

$$
\begin{aligned}
\tilde{\mathrm{k}}^{1}-\tilde{\mathrm{k}}^{0} & =\tilde{\mathrm{k}}\left(\mathrm{p}, \mathrm{r}, \ell^{1}\right)-\tilde{\mathrm{k}}\left(\mathrm{p}, \mathrm{r}, \mathrm{g}\left(\ell^{1}+\ell^{*}\right)\right) \\
& =\left[\tilde{\mathrm{k}}^{1}-\mathrm{k}\right]+\left[\mathrm{k}-\mathrm{g}\left(\tilde{\mathrm{k}}^{1}+\tilde{\mathrm{k}}^{*}\right)\right]=-\mathrm{z}+\mathrm{z}^{\mathrm{E}} .
\end{aligned}
$$

Here $\mathrm{z}$ denotes the vector of home country capital exports and $\mathrm{z}^{E}$ denotes the vector each component of which shows the excess of home ownership of the respective traded factor above the fraction $g$ of the world supply. Let $z^{I}$ be 
defined by

$$
z^{I} \equiv z-z^{E}
$$

Also

$$
\begin{aligned}
y^{l}-y^{0} & =G_{p}\left(p, \tilde{k}^{1}, \ell^{1}\right)-G_{p}\left(p, \tilde{k}^{0}, \ell^{0}\right)=y^{1}-g\left[G_{p}\left(p, \tilde{k}^{1}, l^{1}\right)+G_{p}\left(p, \tilde{k}^{*}, \ell^{*}\right)\right] \\
& =\left(y^{1}-c\right)+c-g\left(y^{1}+y^{*}\right)=x-x^{P}=x^{I} .
\end{aligned}
$$

Thus we have

$$
\left(x^{I}, z^{I},\right) R\left[\left(\ell^{1}-B\left(\ell^{1}+\ell^{*}\right)\right]>0\right. \text {. }
$$

This is the generalized quantity version of the Heckscher-Ohlin theorem. It says that the induced net exports of goods and the $z^{I}$ portion of the net export of capital are positively correlated with the country's relative abundance of the nontraded factors utilized relatively intensively. Equation (45) decomposes total factor trade $z$ into what we call "endowment factor trade" $\mathrm{z}$ and "induced factor trade" $z$. The endowment trade component is the direct result of the extent to which the country's ownership of traded factors is not proportional to the world supply of these factors. This trade is independent of factor intensities (and technology generally), of tastes, of prices, and of endowments of nontraded factors, except in the indirect sense that all these help to determine the factor of proportionality $g$, which depends upon the actual equilibrium. By contrast, induced factor trade $\mathrm{z}^{\mathrm{I}}$, which alone enters into (45), is determined, jointly with induced commodity trade, by factor intensities and by endowments of nontraded factors. Ownership of traded factors has no influence (except, again, if it helps determine the general equilibrium). 
Broadly speaking, countries conduct endowment trade directly to export abundant traded factors and to import scarce traded factors, and they conduct induced factor trade indirectly to export abundant nontraded factors and to import scarce nontraded factors -- in the form of those traded factors which best substitute for them in the production process. Both components of total factor trade thus have a factor-endowment base.

Note the analogy between the two types of goods trade and the two types of factor trade. Induced goods trade, like induced factor trade, is determined by relative factor intensities as summarized in (45). Preference (goods) trade reflects taste differences just as endowment (factor) trade reflects ownership differences. If tastes are identical and homothetic, and if the home and foreign countries own traded factors in identical proportions, (45) describes all trade. It is common to use the term "demand reversal" to describe a situation where taste differences cause the opposite pattern of commodity trade (in a $2 \times 2$ world) to that predicted on the basis of relative factor endowments. We can analogously use the term "demand-endowment reversal" to refer to the case where $x^{P}$ and $z^{E}$ are such that $\left(x^{*}, z^{-}\right) R\left[l^{l}-g\left(l^{l}+\ell^{*}\right)\right]<0$. The basic result ( 45 ) allows joint production, is valid no matter how great the difference between home and foreign endowments, requires no restrictions on dimensionality, and imposes no additional restrictions on technology (such as ruling out higher dimensional analogs of factor-intensity reversals). To proceed further, suppose that the number of sectors equals the number of goods, that there are at least as man goods and traded factors as there are factors, and that in the free trade equilibrium the home and 
foreign endowments of nontraded factors lie in a common generalized

diversification cone (so that there is factor price equalization). If we now apply to (38a) the same logic that we applied to (36) in order to derive (45) we obtain

$$
\left[e^{1}-g\left(e^{1}+\ell^{*}\right)\right]-\left[-C_{w} C_{p}^{-1}\right] x^{I}>0
$$

Thus a country will on average export those goods which make relatively intensive use of the country's relatively abundant nontraded factors. (This of course applies only to induced trade. We describe as a "demand reversal" the case where substitution of $x$ for $x^{I}$ in (46) reverses the direction of the inequality.)

Note two aspects of this result. First, the concept of relative factor intensity employed here is the most natural one: simply the relative sizes of the direct nontraded-factor input requirements of the techniques actually in use. Second, note that only the endowments of nontraded factors, and only that part of the input matrix pertaining to nontraded factors, enter into (46). Changes in the ownership of traded factors, or technological changes which do not influence the use of nontraded factors, will produce no effect. That is, (46) establishes a sense in which the pattern of induced commodity trade, on average, cannot be reversed by such changes, even if the trade vector $x^{I}$ changes. But such a reversal could result from a change in the traded status of a factor, ${ }^{19}$ since such a change would add or subtract from the matrix in (46). 
Expression (46) can be interpreted, in the customary way, as saying that commodity trade substitutes for the exchange of nontraded factors. A similar relation can, surprisingly, be established between (induced) goods trade and actual (induced) factor trade. Using (38b) in the same way that we have used $(38 a)$ and (36) leads to

$$
\text { (47) } \quad \mathrm{z}^{\mathrm{I}}-\left[-\mathrm{C}_{\mathrm{r}} \mathrm{C}_{\mathrm{p}}^{-1}\right] \mathrm{x}<0
$$

This says that a country on average exports those goods that make relatively intensive use of those factors that are imported in excess of endowment trade. That is, induced trade in goods and the induced exchange of traded factors are, in a sense, substitutes. 20 Note that, again, the relevant concept of factor intensity is the relative size of the direct traded-factor inputs of the techniques actually used. Also, the part of the technology pertaining to nontraded factors does not enter at all.

Indeed, under present assumptions, this basic substitution property can be made more exact. We first note that the well-known Travis-Vanek theorem ${ }^{21}$ extends to encompass factor trade in a straightforward way. Induced goods trade would enable the home country to consume the fraction $g$ of the world output of each good. Factor price equalization then implies that these consumed goods would embody the services of the fraction $g$ of the world's stock of each factor, traded or nontraded. Let $x^{\ell} \equiv-C_{w} C_{p}^{-1} x^{I}$ and $x^{k} \equiv-C_{r} C_{p}^{-1} x^{I}$ denote the nontraded-factor and traded-factor content of induced goods trade. Then 


$$
x^{\ell}=\ell^{1}-g\left(\ell^{1}+\ell^{*}\right) \text { and } x^{k}=\left(k^{1}-z\right)-g\left(k^{1}+k^{*}\right) \text {, }
$$

by our generalized Travis-Vanek theorem. Thus

$$
x^{k}=k^{l}-g\left(k^{1}+k^{*}\right)-z=z^{E}-z=-z^{I} \text {. }
$$

That is, induced factor trade is equal to and opposite in sign to the traded factor content. of induced goods trade.

\section{Summary and Conclusions}

Factor price equalization for nontraded factors, with trade in goods and some factors, results if the number of distinct sectors with positive value added is at least as large as the number of nontraded factors and if each country's endowment of nontraded factors is in the generalized diversification cone. If there is no joint production, this requires the number of goods and traded factors to be at least as large as the total number of factors, that is, the number of international markets should be at least as large as the number of factors. The introduction of nontraded goods does not change this result.

Factor price equalization does not per se depend on the (rather arbitrary) relative number of goods and factors but instead on the (less arbitrary) relative number of international markets and factors.

Next we examined the Rybczynski and Stolper-Samuelson theorems. The usual reciprocity relations hold between the effect on output of factor input variations (at constant goods prices) and the effect on factor prices of goods 
price variations (at constant factor input), independently of whether some factors are traded or not. We also derived additional reciprocity relations, between the effect on traded factor inputs of nontraded factor input variations (at constant goods and traded factor prices) and the effect on nontraded factor prices of variations in traded factor prices (at constant nontraded factor input).

The "magnitude" aspects of the Rybczynski and Stolper-Samuelson theorems require the conditions for nontraded factor price equalization to hold in full strength, that is, there should be at least as many international markets as factors. Even without nontraded-factor price equalization, each traded factor is an "enemy" to some nontraded factor, in that the nontraded factor's price mast fall if the traded factor's price increases. By the reciprocity relations, the demand for any traded factor is reduced by the endowment of some single nontraded factor.

We derived a general (directional) Rybczynski theorem: any change in the endowment of nontraded factors will, at constant goods and traded factor prices, tend on the average to raise the most the output of those goods, and to reduce the most the usage of those traded factors, that use relatively intensively those nontraded factors which increase the most. Here, "relative intensity" is defined from the sign pattern of the generalized Pybczynski matrix of the national product function. This result is extremely general in that it allows joint production, applies to arbitrary endowment changes, and is independent of the relative numbers of goods, traded factors, and nontraded factors. 
If the conditions for factor price equalization hold, the above theorem holds for relative intensity defined from the direct nontraded factor input coefficients.

We also derived a (directional) Stolper-Samuelson theorem that a change in goods and traded-factor prices on average increases the most the prices of those nontraded factors used relatively intensively by the goods and traded factors whose prices increase the most.

Finally, we looked at patterns of trade in goods and factors. The principle of comparative advantage extends in straightforward fashion to encompass factor trade. The price version of the Heckscher-Ohlin theorem is, however, rather weak. The quantity version fares better. Decomposing factor trade into "endowment trade" and "induced trade", with the former due to the country's endowment of traded factors not being proportional to world endowments of traded factors, induced factor trade is positively correlated with the relatively abundant nontraded factors used relatively intensively • Decomposing goods trade into "preference trade" and "induced trade", with the former reflecting taste differences, we derived a quantity version of the Heckscher-Ohlin theorem: the induced net export of goods and induced factor trade are positively correlated with a country's relative abundance of the nontraded factors used relatively intensively. This result is again very general, allows for joint production, arbitrary differences between home and foreign endowments, and requires no restriction on dimensionality. Assuming nontraded factor price equalization, the theorem holds for relative intensities defined by direct nontraded factor input coefficients. We also demonstrated 
that in general induced goods trade and induced factor trade are substitutes, and we established the precise sense in which this is so. The Travis-Vanek theorem was extended to factor trade, under nontraded-factor price equalization. The basic theorems of international trade, suitably interpreted, hold with both goods trade and factor trade. In particular, with at least as many distinct sectors as goods, the crucial dimensionality condition under which the theorems hold in their strong versions is that the number of international markets for goods and traded factors be at least as large as the total number of factors. Hence, the crucial issue is not the relative number of goods and factors per se but rather the number of markets. Of the central proposition, only the price version of the Heckscher-Ohlin theorem fails to be essentially preserved by this condition. 


\section{$\underline{\text { Footnotes }}$}

* This paper was written while Lars Svensson was visiting NBER. We thank NBER for providing secretarial assistance.

1. This point is stressed in Jones and Scheinkmen (1977).

2. Earlier treatments of factor-price equalization and factor mobility may be found in Rodriguez (1975), Neary (1980), Svensson (1982), and Ethier $(1982 b)$.

3. See Chang, Ethier and Kemp (1980) for a discussion of how joint production affects the basic theorems of international trade in goods.

4. We shall let subindices denote (the vector of) partial derivatives, throughout. We disregard corner solutions.

5. We assume that these functions exist and are differentiable. However $\tilde{G}_{p}$ and $\tilde{G}_{r}$-- and therefore $x$ and $z$-- may not be uniquely defined (for example, if the technology possesses constant returns to scale and there are at least as many goods as factors). We address this below when it becomes relavant.

6. The purpose of the restriction $w^{-} d v=0$ is to prevent the endowment change from disturbing demands, at constant prices, by redistributing incomes across countries. But this does not, in fact, limit the applicability of our analysis because the original position was itself a rbitrary except for the requirement that endowments be proportional. Thus we could make the initial international income distribution equal to whatever we wish. 
7. From (1) we have $\tilde{G}_{\ell}=G_{k}-\tilde{k}_{\ell}+G_{\ell}-r \tilde{k}_{\ell}=G_{\ell}(p, \tilde{k}(p, r, \ell), \ell)$ and hence $\tilde{G}_{\ell k}=0$ since $\tilde{k}(p, r, l)$ does not depend on $k$.

8. See Woodland (1977).

9. We let $J$ and $J(Y)$ denote both sets of sectors and the number of elements of each set.

10. Equation (19) is in $p, r$, and $w$ only. Hence, for constant $p$ and $r, w$ does not depend on $\ell$.

11. This means that the set $J(Y)$ remains unchanged.

12. See Woodland (1977) for properties of the unit value cost function.

13. For discussions of the new issues which nontraded goods introduce, and of the changes they imply for standard propositions, see Ethier (1972), Flam (1979), and Woodland (1982, Ch. 5).

14. See Ethier (1982b) for a detailed discussion. The implications of joint production are discussed in Chang, Ethier and Kemp (1980) and in Woodland (1982).

15. See Ethier (1982b) for details.

16. Except, of course, where the validity of Rybczynski-type correlations depends upon dimensionality, in which case condition (31) becomes relevant as discussed above.

17. For marginal differences in factor endowments that fulfill (10), one can derive the relations $d x=\tilde{G}_{p v} d v=\left(G_{p k} \tilde{k}_{\ell}+G_{p \ell}\right) d \ell$ and $d z=d k-\tilde{k}_{\ell} d l$, which are extensively discussed in Svensson (1982). There, traded and nontraded factors are said to be "cooperative" ("noncooperative") if the corresponding elements of the matrix $\tilde{\mathrm{k}}_{\ell}$ are positive (negative). Hence, 
traded and nontraded factors being noncooperative corresponds, in the present terminology, to nontraded factors being relatively intensively employed in the usage of traded factors.

18. See Kemp (1976, Part Two) and references cited therein.

19. An example may be found in Svensson (1982).

20. Note that we are referring to the structure of comodity trade and not to its aggregate size. The volume of goods trade may be either larger or smaller in the presence of factor trade than it would be without such trade. This alternative notion of substitutability/complementarity is a nalyzed in Markusen (1983) and Svensson (1982).

21. See Vanek (1968). 


\section{$\underline{\text { References }}$}

Chang, W.W., W.J. Ethier and M.C. Kemp, 1980, The theorems of international trade with joint production, Journal of International Economics 10 , $377-394$.

Deardorff, A.V., 1980, The general validity of the law of comparative advantage, Journal of Political Economy 88, 941-957.

Dixit, A.K. and V. Norman, 1980, Theory of international trade, Cambridge: Nisbet and Cambridge U.P.

Dixit, A.K. and A.D. Woodland, 1982, The relationship between factor endowments and commodity trade, Journal of International Economics 13, $201-214$.

Ethier, W.J., 1972, Nontraded goods and the Heckscher-Ohlin model, International Economic Review 13, 132-147.

Ethier, W.J., 1982a, The general role of factor intensity in the theorems of international trade, Economics Letters 10, 337-342.

Ethier, W.J., 1982b, Higher dimensional trade theory, IIES Seminar Paper No. 218, to appear as Chapter 3 in Jones and Kenen (1983).

Flam, H., 1979, The Rybczynski theorem in a model with nontraded goods and indecomposable inter-industry flows, International Economic Review 20, $661-670$.

Jones, R.W. and P.B. Kenen, eds., 1983, Handbook of International Economics, vol. 1, Amsterdam: North-Holland, forthcoming. 
Jones, R.W. and J.P. Neary, 1982, The positive theory of international trade, to appear as Chapter 1 in Jones and Kenen (1983).

Jones, R.W. and J. Scheinkman, 1977, The relevance of the two-sector production model in trade theory, Journal of Political Economy 85, 909-935.

Kemp, M.C., 1976, Three Topics in the Theory of International Trade, Amsterdam: North-Holland.

Markusen, J.R.; 1983, Factor movements and commodity trade as complements, Journal of International Economics, forthcoming.

Neary, J.P., 1980, International factor mobility, minimum wage rates and factor price equalization, IIES Seminar Paper No. 158. Rodriguez, C.A., 1975, International factor mobility, non-traded goods, and the international equalization of prices of goods and factors, Econometrica 43, 115-124.

Svensson, L.E.O., 1982, Factor trade and goods trade, NBER Working Paper No. 999.

Vanek, J., 1968, The factor proportions theory: the n-factor case, Kyklos 28, 749-755. Woodland, A.D., 1977, Joint outputs, intermediate inputs and international trade theory, International Economic Review 18, 517-533. Woodland, A.D., 1982, International Trade and Resource Allocation, Amsterdam: North-Holland. 